\title{
Mdm2 and MdmX RING Domains Play Distinct Roles in the Regulation of p53 Responses: A Comparative Study of Mdm2 and MdmX RING Domains in U2OS Cells
}

\author{
Olga Egorova, Heather HC Lau, Kate McGraphery and Yi Sheng * \\ Department of Biology, York University, 4700 Keele Street, Toronto, ON M3J 1P3, Canada; \\ olga-egorova@hotmail.com (O.E.); heather.lau@mail.utoronto.ca (H.H.L.); kate.mcgraphery@gmail.com (K.M.) \\ * Correspondence: yisheng@yorku.ca; Tel.: +1-416-736-2100 (ext. 33521)
}

Received: 10 January 2020; Accepted: 9 February 2020; Published: 15 February 2020

check for updates

\begin{abstract}
Dysfunction of the tumor suppressor p53 occurs in most human cancers. Mdm2 and $\mathrm{MdmX}$ are homologous proteins from the Mdm (Murine Double Minute) protein family, which play a critical role in p53 inactivation and degradation. The two proteins interact with one another via the intrinsic RING (Really Interesting New Gene) domains to achieve the negative regulation of p53. The downregulation of p53 is accomplished by Mdm2-mediated p53 ubiquitination and proteasomal degradation through the ubiquitin proteolytic system and by Mdm2 and MdmX mediated inhibition of p53 transactivation. To investigate the role of the RING domain of Mdm2 and MdmX, an analysis of the distinct functionalities of individual RING domains of the Mdm proteins on p53 regulation was conducted in human osteosarcoma (U2OS) cell line. Mdm2 RING domain was observed mainly localized in the cell nucleus, contrasting the localization of MdmX RING domain in the cytoplasm. Mdm2 RING was found to possess an endogenous E3 ligase activity, whereas MdmX RING did not. Both Mdm2 and MdmX RING domains were able to dimerize with endogenous full-length Mdm2 and $\mathrm{MdmX}$ protein and affect their cellular function. The results showed that overexpression of the Mdm2 or MdmX RING domains interfered with the endogenous full-length Mdm2 and MdmX activity and resulted in p53 stabilization and p53 target gene activation. However, both Mdm RING domains showed oncogenic activity in a colony formation assay, suggesting that the Mdm RING domains possess p53-independent oncogenic properties. This study highlights the distinct structural and functional traits of the RING domain of Mdm2 and MdmX and characterized their role in cellular responses through interfering with p53 dependent signaling pathway.
\end{abstract}

Keywords: Mdm2; MdmX; RING domain; the ubiquitin proteolytic system

\section{Introduction}

The tumor suppressor protein p53, known as the "guardian of the genome", is dysfunctional in most of human cancers. As a key transcriptional factor, p53 orchestrates cellular responses to DNA damage, nutrient depletion, and abnormal oncogenic events by regulating diverse signaling pathways [1-3]. Loss of p53 function causes genomic instability and malignant transformation [4-7]. In normal cells, p53 is tightly regulated by two MDM (Murine Double Minute) family proteins: Mdm2 and MdmX. $\mathrm{Mdm} 2$ and MdmX are homologous in both structure and function, each containing an N-terminal p53 binding domain and a C-terminal RING domain. The two proteins form a dimeric complex through interaction of their RING domains, nevertheless, play non-redundant roles in regulating p53 function [8]. Recent research suggests that Mdm2 primarily inhibits p53 by ubiquitination of p53, which leads to p53 nuclear export and proteasomal degradation $[9,10]$. MdmX, on the other hand, lacks E3 
ligase activity and inhibits p53 through blockade of the transactivation activity of p53 [8,11]. Functional disparity of Mdm2 and MdmX is supported by the mouse knockout studies [12-15], in which deletion of MDM2 or MDMX resulted in embryonic lethality that could be rescued by concomitant deletion of TP53. Phenotypically, MDM2 knockout showed prevalent apoptosis, whereas MDMX knockout caused primarily cell cycle arrest in these genetic studies $[11,16,17]$. These genetic studies suggest that $\mathrm{Mdm} 2$ and MdmX cannot compensate each other and each serves a unique role in the regulation of p53.

Further genetic knock-in studies revealed an interconnected and dependent nature of Mdm2 and MdmX function in vivo. Importantly, deletion of the MDMX RING or mutation that impairs Mdm2/MdmX dimerization caused embryonic lethality, which could only be rescued by concomitant TP53 knockout, despite Mdm2 E3 ligase activity and the ability to interact with p53 were maintained for the mutants $[11,18,19]$. This study further demonstrates the functional importance of the Mdm2/MdmX heterodimer formation via the RING domain in vivo. Although Mdm2 and MdmX RING domains can interact and form both homo- and heterodimers, MdmX appears to depend on Mdm2 for p53 regulation due to the lack of an NLS signal and intrinsic E3 ligase activity. Through the interaction with Mdm2, MdmX relocates to the nucleus and functions as a negative regulator for p53 transactivation [20]. In vitro studies suggest that $\mathrm{MdmX}$ works as a competitive substrate for Mdm2 activity, which results in a more stabilized Mdm2/MdmX ligase complex [19,21,22]. In addition, Mdm2 and MdmX possess p53-independent functions, which contribute to their nonoverlapping physiological roles in the cell. Acting as an E3 ligase, Mdm2 targets a number of cellular proteins for proteasomal degradation, including Foxo3A, pRB, and E-cadherin [23-25]. MdmX could interact with mTOR to affect metabolic pathways by impairing mTORC1 activity [26].

Aberrant splice variants of the MDM2 and MDMX genes have been identified from various aggressive forms of cancers. However, the functions of these splice variants remain poorly understood. For instance, MDM2-A and HDM2 ${ }^{\mathrm{ALT} 1}$ are the MDM2 gene products characterized as lacking the N-terminal p53 binding domain, however, containing the complete C-terminal RING domain [27-30]. Similarly, the MDMX gene splice variant, HDMX211, misses an N-terminal p53-binding domain, but possesses an intact C-terminal RING domain [31]. These splice variants can potentially interact with $\mathrm{Mdm} 2$ and $\mathrm{Mdm} X$ in vivo through dimerization and affect Mdm2/MdmX-dependent suppression of p53 function. However, studies towards understanding the activity and function of these Mdm variants have been inconclusive. In this study, we compared the functions of the Mdm2 and MdmX RING domains and their effects on p53 stabilization and transactivation in a human osteosarcoma U2OS cell line. We show that Mdm2 and MdmX RING domains possess distinct functions in the regulation of the endogenous Mdm2, MdmX, and p53 activity.

\section{Results}

\subsection{Cellular Localization of the Ectopically Expressed Mdm2 and MdmX RING Domains in U2OS Cells}

To better understand the functions of Mdm2 and MdmX RING domains, we ectopically expressed the minimal RING domain regions of Mdm2 (Mdm2 RING, residues 417-490) and MdmX (MdmX RING, residues 416-491) as YFP fusion proteins in U2OS cells (Figure 1A). Fluorescence microscopic results showed that Mdm2 RING localized predominantly in the nucleus, while MdmX RING expressed primarily in the cytoplasm, with some weak staining detected in the nucleus (Figure 1B). To compare the subcellular localization of Mdm2 and MdmX RING domain localization with their full-length counterparts, the full-length Mdm2 (Mdm2 FL) and MdmX (MdmX FL) were tagged with CFP and expressed in U2OS cells. Consistent with the previous studies, CFP-Mdm2 FL was found exclusively in the nucleus, while CFP-MdmX FL localized in both the cytoplasm and nucleus (Figure 1B). 

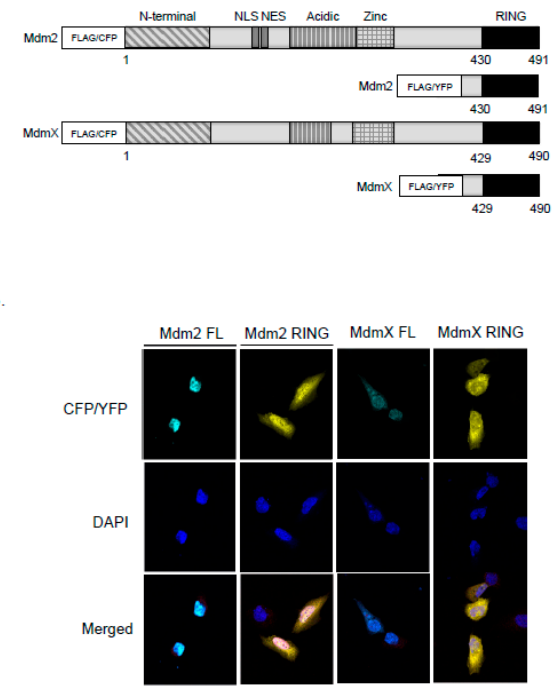

C.
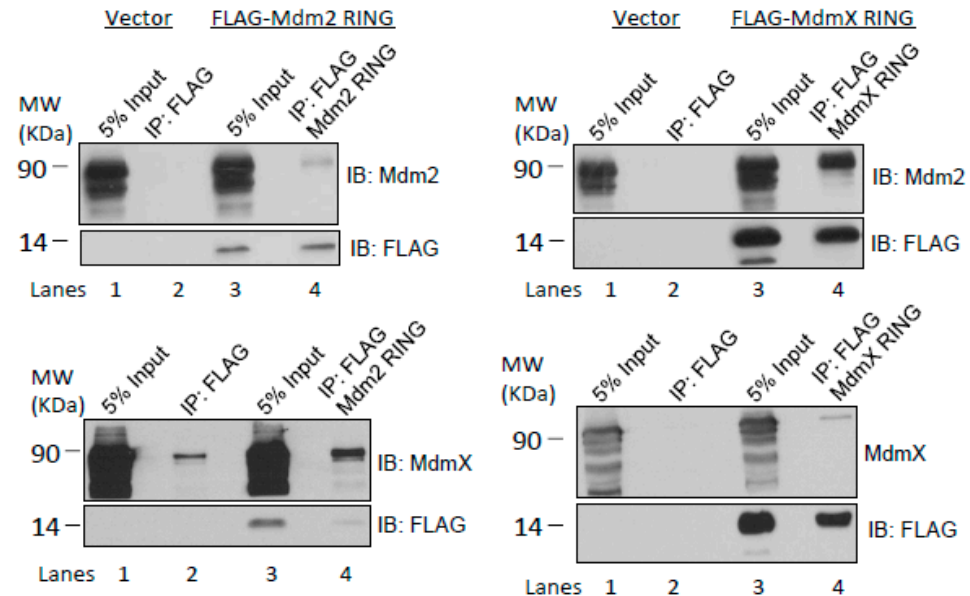

Figure 1. Cellular localization and interaction of the ectopically expressed Mdm2 RING and MdmX RING domains. (A) Domain arrangement of Mdm2 and MdmX proteins and constructs used in this study. Both Mdm2 and MdmX possess $\mathrm{N}$-terminal p53-binding domains (N-terminal), central acidic domains (Acidic), zinc finger domains (zinc), and C-terminal RING domains (RING). Mdm2 alone contains a nuclear localization signal (NLS) and a nuclear export sequence. Numbers indicate amino acid residue positions. Wild type full-length $\mathrm{Mdm} 2$ and $\mathrm{Mdm}$ X were expressed as FLAG- or CFP-fusion proteins; Mdm2 and MdmX RING were expressed as FLAG- or YFP-fusion proteins. (B) U2OS cells were transfected with CFP-Mdm2, CFP-MdmX, YFP-Mdm2 RING, and YFP-MdmX RING. Cells were fixed at $24 \mathrm{~h}$ post-transfection. Nuclei were stained with DAPI. Results indicate nuclear localization of the full-length Mdm2 and overlapping nuclear and cytoplasmic localization of the full-length MdmX, Mdm2 RING, and MdmX RING domains. Scale bars represent $5 \mu \mathrm{M}$. (C) Co-immunoprecipitation of Mdm2 and MdmX with Mdm2 RING and MdmX RING. U2OS cells were co-transfected with an empty FLAG vector, Mdm2 FL, MdmX FL, FLAG-Mdm2 RING, or FLAG-MdmX RING as indicated to examine the interaction between Mdm RINGs and the full-length Mdm proteins. Co-immunoprecipitation was carried out $24 \mathrm{~h}$ post-transfection using a polyclonal anti-FLAG antibody. Immunoblotting was carried out with Mdm2, MdmX and FLAG specific antibodies. 


\subsection{Mdm2 RING and MdmX RING Domains Interact with the Full-Length Mdm2 and MdmX}

Mdm2 and MdmX RING domains have been identified as the functional domain in several aberrant splice variants of Mdm2 and MdmX identified from cancers, such as HDM2 ${ }^{\mathrm{ALT} 1}$ and HDMX211 [27,31,32]. These variants are expected to affect the functions of endogenous Mdm2 and MdmX by interactions via their RING domains. To examine the interactions of the full-length Mdm2 and MdmX with the Mdm2 and MdmX RING domains in the cell, co-immunoprecipitation experiments were conducted using the U2OS cell line. U2OS cells were co-transfected with full-length Mdm2 or MdmX and FLAG-tagged Mdm2 or MdmX RING domains. As shown in Figure 1C, FLAG-tagged Mdm2 RING domain could readily pull down both Mdm2 FL and MdmX FL. Similarly, FLAG-tagged MdmX RING domain immunoprecipitated both Mdm2 FL and MdmX FL. These results supported the notion that Mdm2 RING and MdmX RING could form dimers with Mdm2 FL and MdmX FL via their C-terminal RING domains. Interestingly, we observed that more MdmX FL was immunoprecipitated by Mdm2 RING domain and more Mdm2 FL was immunoprecipitated by MdmX RING domain, implying that both Mdm2 and MdmX RING domains favor formation of heterodimers.

\subsection{Ectopically Expressed Mdm2 and MdmX RING Domains Affect the Stability and Function of Endogenous} $M d m 2$ and $M d m X$

To explore the functions of the isolated Mdm2 and MdmX RING domains, we overexpressed Mdm2 or MdmX RING, and examined their individual effect on the endogenous Mdm2 and MdmX proteins. Overexpression of Mdm2 RING decreased the cellular level of Mdm2 (Figure 2A, middle two lanes). Treatment with MG132, a proteasome inhibitor, restored the level of endogenous Mdm2 in Mdm2 RING overexpressing cells, suggesting Mdm2 RING domain could destabilize the endogenous Mdm2 protein via proteasomal degradation (Figure 2B and Figure S1). Interestingly, Mdm2 RING domain overexpression elevated the endogenous MdmX level and treatment with MG132 further stabilized MdmX, suggesting that the Mdm2 RING domain could cause MdmX proteasomal degradation, but less active than the full-length Mdm2. In the normal cells, endogenous MdmX is dimerized with and degraded by Mdm2. The overexpressed Mdm2 RING could interact with endogenous MdmX and sequester it away from the endogenous Mdm2-mediated degradation. Overexpression of MdmX RING domain stabilized both endogenous Mdm2 and MdmX, whereas MG132 treatment had no effect on levels of endogenous Mdm2 and MdmX (Figure 2A,B). This agrees with inactivity of the MdmX RING as an E3 ligase, and supports its role as a dominant negative of endogenous Mdm2 and MdmX. Its interaction with endogenous Mdm2 and MdmX blocks Mdm2 and MdmX degradation. Lastly, we examined the ability of Mdm2 and MdmX RING domains to ubiquitinate endogenous p53 (Figure 2C). As expected, only the full-length Mdm2 showed activity in polyubiquitination of p53, whereas Mdm2 RING and MdmX RING domains lacking p53-binding sites could not ubiquitinate p53. 
A.

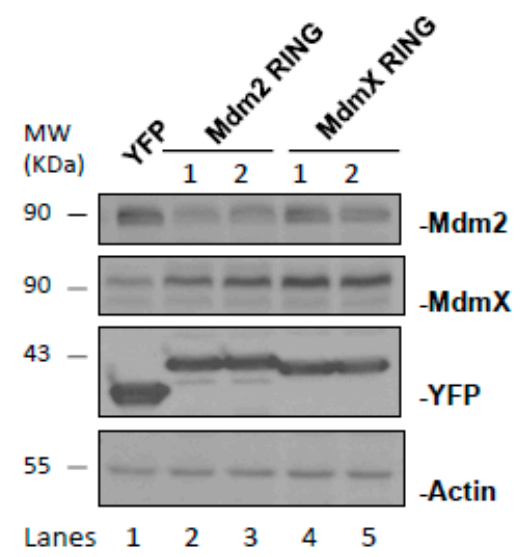

C.

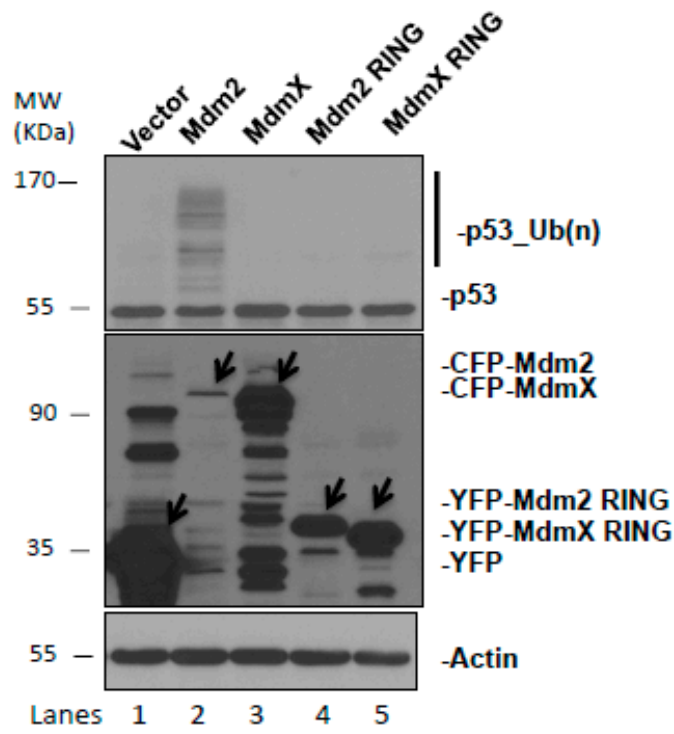

B.

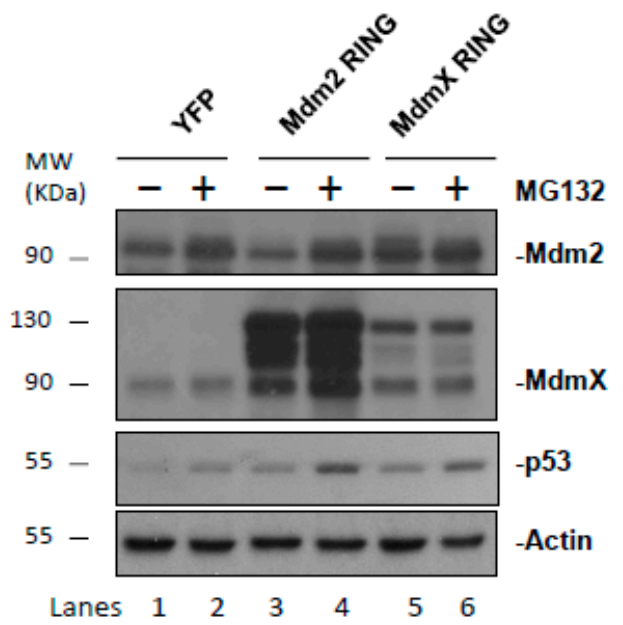

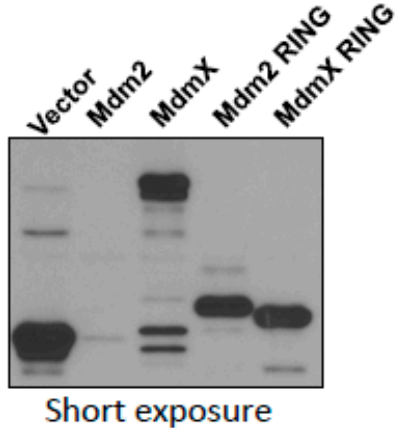

Short exposure

Figure 2. Effects of the ectopically expressed Mdm RING domains on p53 ubiquitination and endogenous levels of Mdm2 and MdmX. (A) U2OS cells were transfected with YFP-Mdm2 RING, and YFP-MdmX RING. The total cell lysate was immunoblotted for the protein levels of full-length Mdm2 and MdmX. (B) U2OS cells were transfected with YFP-Mdm2 RING and YFP-MdmX RING. The total cell lysate was immunoblotted for the protein levels of full-length $\mathrm{Mdm} 2, \mathrm{MdmX}$ and p53, and compared in the absence and presence of the proteasome inhibitor MG132 treatment. (C) U2OS cells were transfected with CFP-Mdm2, CFP-MdmX, YFP-Mdm2 RING, and YFP-MdmX RING. The total cell lysate was immunoblotted for the p53 ubiquitination. The arrows indicate ectopically expressed proteins.

2.4. Effect of the Ectopic Mdm2 and MdmX RING Domains on the Cellular Level of p53 under Normal and DNA Damage Conditions

As both Mdm2 and MdmX are actively involved in the DNA repair-signaling pathway through p53, the isolated Mdm2 and MdmX RING domains are expected to affect p53 signaling through the interactions with endogenous Mdm2 and MdmX. To study functions of the Mdm2 and MdmX RING domains in the p53 response pathway, FLAG-tagged Mdm2 and MdmX RING were ectopically expressed in U2OS cells, and full-length FLAG-tagged Mdm2 and MdmX were included as positive controls (Figure S2). The effect of the ectopically expressed Mdm2 and MdmX RING on the levels of endogenous Mdm2 and MdmX were tested under DNA damage induced by doxorubicin, an inhibitor of DNA topoisomerase II. Exogenous protein expression was determined with immunoblotting using antibodies against a FLAG-tag. Both FLAG-Mdm2 FL and RING were expressed at low levels compared 
to MdmX, suggesting that FLAG-Mdm2 FL and RING contained the active RING domain and were less stable (Figure S2).

Consistent with the results obtained using YFP-fusion proteins, the MdmX RING domain stabilized both endogenous Mdm2 and MdmX. However, the effect of the Mdm2 RING domain on endogenous Mdm2 and MdmX was not obvious (Figure 3A). The discrepancy might be explained by the relative stoichiometric ratios of the ectopically expressed Mdm2 RING and endogenous Mdm proteins.

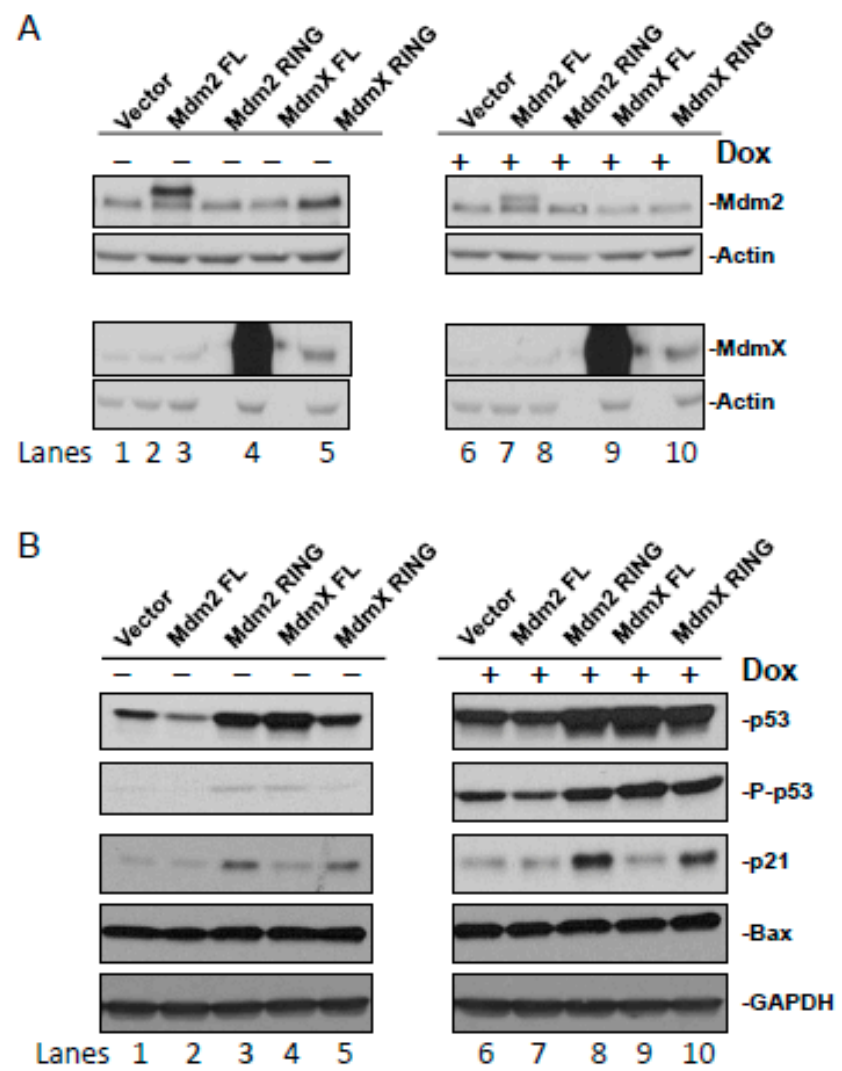

C.
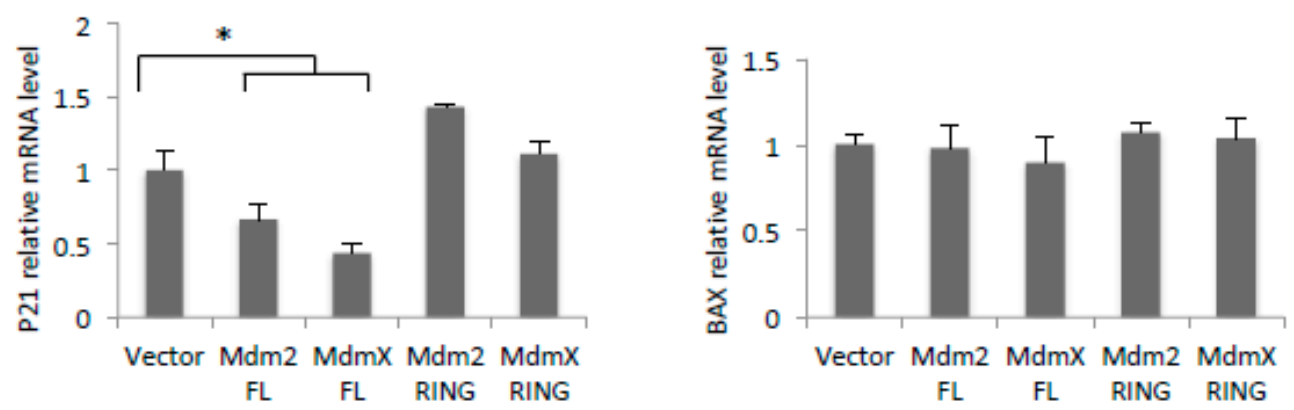

Figure 3. Effects of the ectopically expressed Mdm RING domains on p53 activation. (A) U2OS cells were transfected with FLAG-Mdm2, FLAG-MdmX, FLAG-Mdm2 RING, and FLAG-MdmX RING. The total cell lysate was immunoblotted for the protein levels of full-length Mdm2 and MdmX. (B) U2OS cells were transfected with FLAG-Mdm2, FLAG-MdmX, FLAG-Mdm2 RING, and YFP-MdmX RING. The total cell lysate was immunoblotted for the protein levels of p53, phosphorylated p53 at Ser15, p21, and Bax. (C) U2OS cells were transfected with FLAG-Mdm2, FLAG-MdmX, FLAG-Mdm2 RING, and FLAG-MdmX RING. Relative mRNA expression levels of p21 (CDKN1A) and Bax (BAX) were analyzed. Results are expressed as Mean \pm SEM of three biological replicates. Expression levels of p21 and Bax in the vector control are taken as 1. The results were analyzed using statistical one-way ANOVA test. ${ }^{*} p \leq 0.05$. 
The effect of ectopic expression of the Mdm2 and MdmX FL and RING on the level of total p53 as well as the activated p53 (P-p53, phosphorylated at Ser 15) was examined next. In the absence of DOX, both total and activated p53 levels were stabilized in the presence of the ectopically expressed Mdm2 RING and MdmX FL, whereas MdmX RING stabilized p53 to a lesser extent (Figure 3B). A visible decrease was seen in p53 levels following the overexpression of Mdm2 FL. Following DOX treatment, both total and activated p53 levels were stabilized, and more stabilization was observed in the cells ectopically expressing Mdm2 RING, MdmX RING, and MdmX FL (Figure 3B). Overexpression of $\mathrm{Mdm} 2$ resulted in decreased steady levels of $\mathrm{p} 53$ and phosphorylated p53, agreeing with the role of Mdm2 in p53 ubiquitination and degradation. Overexpression of MdmX FL greatly increased the levels of p53 and phosphorylated p53. It is likely due to the fact that MdmX inhibits p53 transcriptional activity leading to the reduced expression of p53 target genes including Mdm2, while decreased Mdm2 levels further stabilize p53. Consistent with this notion, we observed reduced levels of Mdm2 upon MdmX FL overexpression (Figure 3A, lanes 4 and 9).

\subsection{Effect of the Ectopic Mdm2 and MdmX RING Domains on p53 Target Genes}

External stress stimuli, such as DNA damage, stabilize and activate p53, which in turn regulate transcription of its target genes. To further elucidate the effects of the ectopically expressed Mdm2 and MdmX RING domains on the transcriptional activity of p53, the expression of its downstream target genes, p53-mediated expression of p21 involved in regulation of the cell cycle progression and a proapoptotic Bax protein was investigated (Figure 3B,C) [33,34]. Ectopic expression of Mdm2 RING led to highly increased p21 levels in the presence and absence of DOX. MdmX RING also caused p21 increase, but to a lesser extent compared to Mdm2 RING. The enhancement was considerably greater in the DOX treated samples likely due to the greater amount of activated p53 detected after treatment. In both doxorubicin-untreated and -treated cells, overexpression of Mdm2 FL or MdmX FL led to decreased p21 protein levels. This is consistent with the role of Mdm2 as p53 E3 ligase and $\mathrm{MdmX}$ as a potent inhibitor for p53 transactivation. Similar results were observed for CDKN1A mRNA levels, suggesting that p21 regulation occurs at both the transcriptional and the protein level. However, no changes were observed in Bax protein and mRNA levels as a result of overexpression of the exogenous proteins.

\subsection{Effect of the Ectopic Mdm2 and MdmX RING Domains on U2OS Cell Cycle and Cell Growth}

To examine the effect of ectopic Mdm2 and MdmX RING domains on U2OS cell cycle progression, flow cytometry analysis was carried out following transfection of U2OS cells with the full-length or RING domains of either Mdm2 or MdmX. Cell DNA contents were stained with propidium iodide and analyzed. We did not observe any significant difference in cell cycle profiles as a result of overexpression of the exogenous proteins. The proportion of cells in G1, S, and G2/M was relatively similar for all the constructs (Figure 4A).

To examine the effect of the ectopic Mdm2 and MdmX RING on U2OS cell growth, clonogenic assays were carried out (Figure 4B). As expected, compared to the vector control group, ectopic overexpression of Mdm2 and MdmX FL showed significantly more colony growth over the 10-day-period $(p<0.01)$. Despite the fact that overexpression of Mdm2 and MdmX RING led to p53 stabilization, ectopic expression of Mdm2 and MdmX RING led to increased colony formation by 2-fold and 3-fold, respectively, compared to the control group. This result suggested that both Mdm2 and MdmX RING promoted tumor growth, but MdmX RING was a more potent tumorigenic construct and comparable to Mdm2 and MdmX FL. 
A.

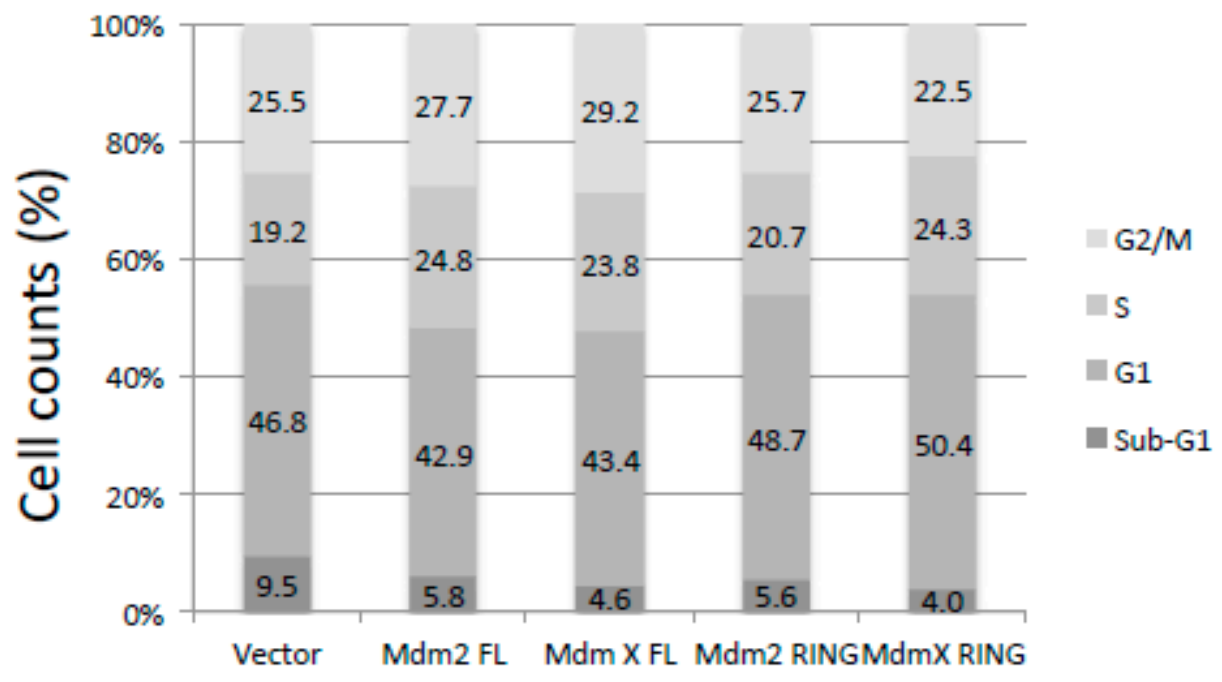

B

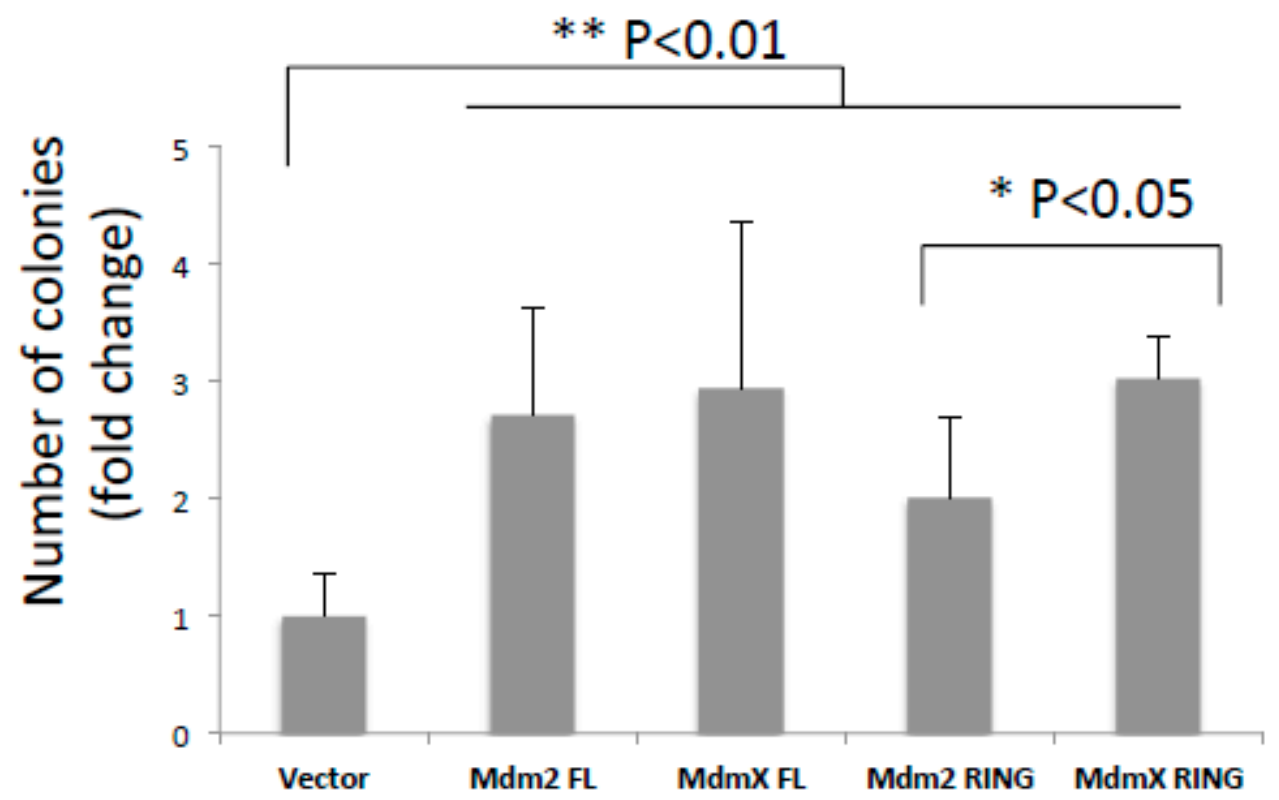

Figure 4. Effects of the ectopically expressed Mdm RING domains on cell cycle and colonogenic activity. (A) U2OS cells were transfected with FLAG vector or FLAG tagged-Mdm2, MdmX, Mdm2 RING, or MdmX RING. After a 24-hour transfection, cells were collected, stained with propidium iodide and analyzed for DNA content using flow cytometry. Percentage distribution of cells in each phase of cell cycle (sub-G1, G1, S, and G2/M) was indicated. (B) Equal number of U2OS cells were seeded after transfection with FLAG vector or FLAG tagged-Mdm2, MdmX, Mdm2 RING, or MdmX RING. Following a 10-day growing period, cells were washed twice and stained with methylene blue dye. Colonies were counted and normalized using vector as reference. The bar graph represents three independent experiments and results were analyzed using statistical one-way ANOVA test. ${ }^{*} p \leq 0.05$; ** $p \leq 0.01$. 


\section{Discussion}

Regulation of p53 by its negative regulators Mdm2 and MdmX is crucial for proper cellular functioning and prevention of tumorigenesis. Mdm2-mediated ubiquitination of p53 remains the main mechanism modulating p53 stability through proteasomal degradation. Mdm2 and MdmX share the most similarity in their RING domains. However, only Mdm2 possesses E3 ligase activity through its RING domain, whereas MdmX carries an inactive RING domain [21,35-37]. It is also observed that many human and murine tumors express truncated Mdm2 and MdmX variants, often only containing intact RING domains [27,30-32,38]. It is unclear how these Mdm2 and MdmX variants affect the endogenous p53 regulation network or what their specific roles are in tumorigenesis. The purpose of this study was to carry out a comparative analysis of the Mdm2 and MdmX RING domains using human cell lines, focusing on their mechanistic and functional differences in p53 regulation. We first examined the subcellular localization of ectopically expressed Mdm2 and MdmX RING and their interaction with endogenous Mdm2 and MdmX through RING domain. We found that Mdm2 RING localized predominantly in the nucleus and preferentially bound to MdmX. In contrast, MdmX RING resided mostly in the cytoplasm with a small proportion in the nucleus and favored the interaction with Mdm2 through RING domain.

Next, we examine the differential function of Mdm2 and MdmX RING in the regulation of endogenous Mdm2 and MdmX. We found that Mdm2 RING possessed an active E3 ligase activity, but showed opposite effects on the levels of endogenous Mdm2 and MdmX. On one hand, it promoted proteasome-mediated degradation of endogenous Mdm2 through its active RING domain. On the other hand, it formed a heterodimer with endogenous MdmX, which resulted in protection of MdmX from degradation by endogenous Mdm2 and subsequent MdmX stabilization. The net outcome may be dependent on the relative stoichiometric ratios of ectopically expressed Mdm2 RING domain and the endogenous Mdm proteins, which would influence the relative E3 ligase activity of the endogenous Mdm2/MdmX complex [25]. We also found that MdmX RING had no intrinsic E3 ligase activity. It served as a dominant negative of endogenous Mdm2 and MdmX through dimerization and caused stabilization of both Mdm2 and MdmX.

Nuclear localization of Mdm2 was previously reported, and transport between the nucleus and the cytoplasm was enabled due to its nuclear localization signal and nuclear export sequence [39]. MdmX did not possess those motifs, thereby mainly localizing within the cytoplasm [20,40]. However, dimerization with Mdm2 via their C-terminal RING domains could allow transport of MdmX into the nucleus [41]. Nuclear localization of the Mdm2 RING and MdmX RING domains could be explained by a complex formation between the exogenous RING domains and the endogenous Mdm2 that could transport them into the nucleus. Uniform localization of the Mdm2 and MdmX RING domains suggested their ability to regulate Mdm2 and MdmX functions within the nucleus and the cytoplasm.

The effects of the ectopic expression of Mdm2 and MdmX RING on p53 and downstream p53 effects were examined in the absence or presence of DNA damage, induced by doxorubicin. Following a 24-hour transfection in human osteosarcoma cells, we observed the effects of the exogenous proteins on the levels of endogenous p53 and its main negative regulators Mdm2 and MdmX. Furthermore, by means of detecting levels of phosphorylated p53 and its downstream gene targets, namely, p21 and Bax, the gene transcription activity of p53 was examined. The effects of the exogenous proteins were compared between normal and stress conditions, triggered by the DNA-damaging agent doxorubicin.

Following ectopic expression of Mdm2 FL under normal or stress conditions, an increased cellular Mdm2 level and decreased endogenous p53, phosphorylated p53, and p21 levels were found. There were no changes in the endogenous levels of MdmX and Bax. Low p53 levels could be explained by the Mdm2-mediated p53 polyubiquitination, which targeted it for the proteasomal degradation. Consequently, low levels of the phosphorylated p53 and p21 were observed. This was further supported by the fact that Mdm2 FL was primarily localized within the nucleus. In addition, several studies showed Mdm2-dependent destabilization of p21, which could also contribute to the observed low p21 level $[42,43]$. 
Overexpression of MdmX FL did not affect levels of endogenous Mdm2 and Bax regardless of doxorubicin administration. Interestingly, under normal conditions, we observed a slight accumulation of p53 and phosphorylated p53, and low levels of p21 expression. Following doxorubicin treatment these effects were not found. Different cell responses to MdmX overexpression indicated functional complexity and differential recruitment of $\mathrm{MdmX}$ in normal and stress conditions. An increase in the levels of p53 and phosphorylated p53 could occur as a result of inhibition of the Mdm2-mediated p53 degradation by means of complex formation between Mdm2 and MdmX. Although, p53 was stabilized in the cell, it was transcriptionally inactive as exemplified by the levels of p21 (Figure 3C). This effect was probably seen due to the MdmX-dependent inhibition of the p53 gene transcription activity through interactions between their N-terminal domains. In addition, low p21 level in a sample with the overexpressed MdmX FL could also be explained by several studies that demonstrated MdmX-mediated p21 degradation independent of p53 [44,45]. Note that in contrast to several studies [41], we did not find $\mathrm{Mdm} 2$ stabilization by $\mathrm{MdmX}$ and efficient p53 degradation by the Mdm2/MdmX heterodimer. The underlying mechanism for this contradiction is not clear; however, it should be addressed in later experiments.

In absence of doxorubicin treatment, ectopically expressed Mdm2 RING domain led to a slight stabilization of endogenous Mdm2 and no changes in MdmX, p53, phosphorylated p53, p21, and Bax levels. Following drug treatment, more efficient stabilization of endogenous Mdm2, an increase in phosphorylated p53 level, and p21 expression were observed. No significant changes in MdmX, p53, and Bax levels were found in presence of a stress signal. Co-immunoprecipitation experiments demonstrated the ability of the overexpressed Mdm2 RING to interact with endogenous full-length Mdm2 and MdmX. Dimerization with Mdm2 could explain nuclear translocation of the exogenous Mdm2 RING from the cytoplasm. Therefore, the observed Mdm2 stabilization in stress conditions could be explained by the dimer formation between endogenous Mdm2 and exogenous Mdm2 RING domain, which led to inhibition of $\mathrm{Mdm} 2$ autoubiquitination activity and its degradation. The cellular response to Mdm2 RING overexpression revealed that Mdm2 RING acted in a dominant negative fashion to suppress endogenous Mdm2 E3 ligase function and specifically in presence of a DNA-damaging signal prevented Mdm2-mediated inhibition of the p53 gene transcription activity.

Under normal and stress conditions, stabilization of endogenous Mdm2 and MdmX as a result of MdmX RING overexpression was observed, whereas there was no effect on p53, phosphorylated p53, and Bax levels. The MdmX RING domain was shown to interact with endogenous full-length Mdm2 and $\mathrm{MdmX}$. Stabilization of endogenous $\mathrm{Mdm} 2$ and $\mathrm{Mdm} X$ could be a consequence of inhibition of the Mdm2 E3 ligase activity by means of complex formation between the ectopically expressed MdmX RING and endogenous Mdm2. These findings indicated that the exogenous MdmX RING domain, like Mdm2 RING, exhibited a dominant negative phenotype inhibiting Mdm2 ubiquitination activity, which in turn resulted in p53 stabilization.

Note that despite the stabilization effect of p53 by overexpression of Mdm2 and MdmX RINGs, they enhanced the clonogenicity of tumor cells in a colony-forming assay. The molecular basis for p53-independent tumor-promoting activity of the Mdm2/X RING domains has not been well studied. However, increasing number of studies revealed p53-independent roles of Mdm2 and MdmX in tumor cells. Indeed, Mdm2 RING possesses nucleotide-binding activity [46]. Acting as a chromatin modifier, $\mathrm{Mdm} 2$ could contribute to tumorigenesis through attenuating DNA damage response, repressing cell differentiation and impairing amino acid metabolism and redox homeostasis [47-49]. Similarly, MdmX could promote genomic instability by association with Nbs1 of the Mre11-Rad50-Nbs1 (MRN) DNA repair complex and inhibition of the DNA damage response in p53- and Mdm2-independent manner [50]. Thus, Mdm2 and MdmX may contribute to tumorigenesis through their RING domain alone.

Collectively, this study implies that Mdm2 RING and MdmX RING function differently but inter-connectively in cells depending on the presence or absence of stress stimuli (Figure 5). As expected, Mdm2 RING and MdmX RING could not ubiquitinate p53. However, they served as inhibitors of the endogenous Mdm2 E3 ligase activity, interfering with the p53/Mdm2/MdmX interaction network. 
Mdm2 RING appeared to be active in mediating Mdm2 degradation through ubiquitin proteolytic system while MdmX RING, lacking E3 ligase activity, stabilized endogenous Mdm2 and MdmX through dimerization. The comparison of the Mdm2 and MdmX RING domains in this study provides functional insight into the role of these RING domains, which is crucial for developing anticancer therapies targeting Mdm2 and MdmX. Note that these findings are based on the overexpression studies using transient transfection, which contain some limitations. Although transient transfection is widely used to study short-term effects in cellular functions [27,51,52], the significance of the long-term effects of Mdm2 and MdmX RING domain on endogenous p53/Mdm2:MdmX remain to be tested in vivo.
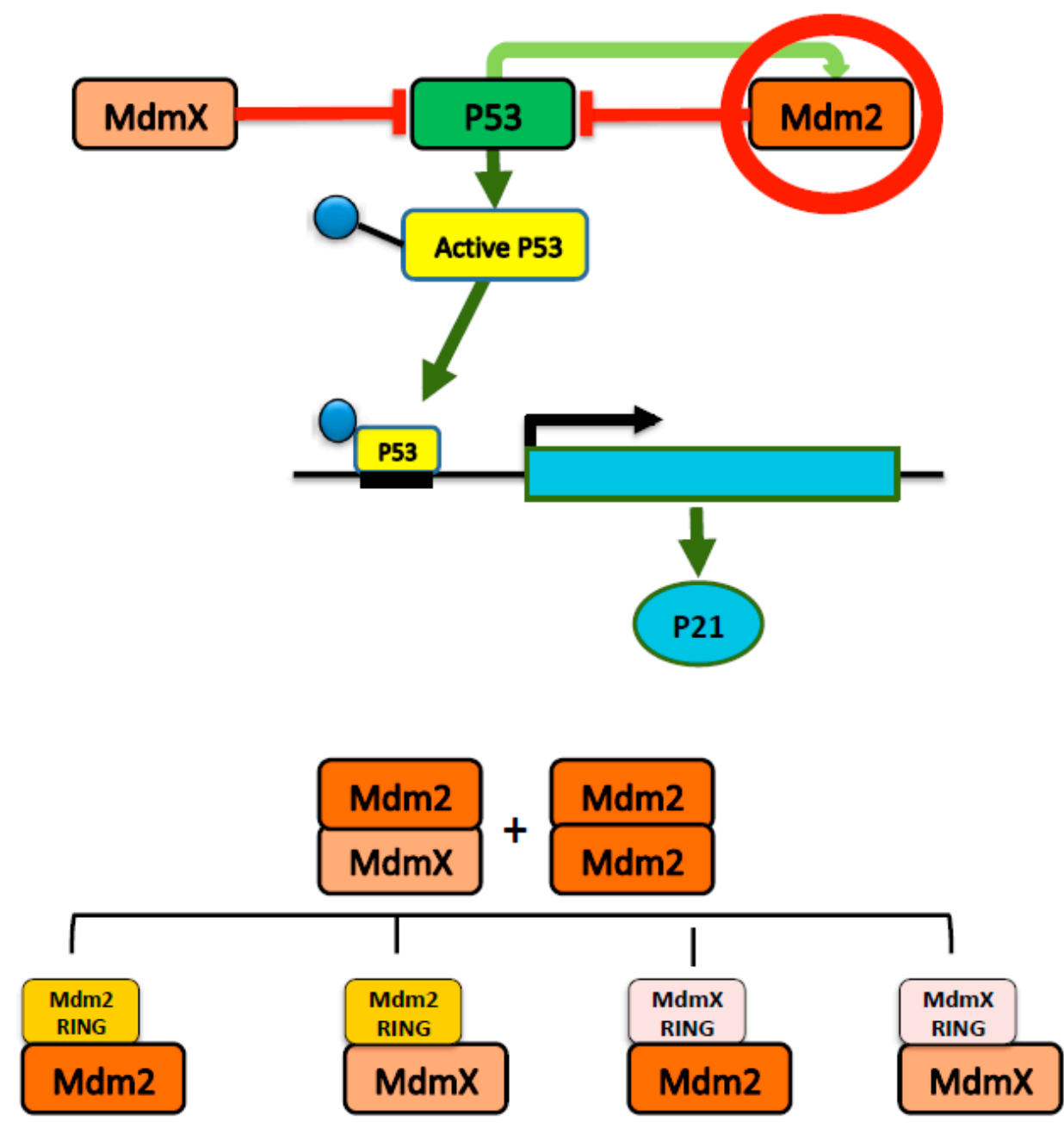

\begin{tabular}{lll} 
Isolated Mdm2 RING domain & & Isolated MdmX RING domain \\
\cline { 1 - 2 } Nucleus & & Cytoplasm \\
Active E3 ligase & & Inactive E3 ligase \\
Promote p53 stabilization & & Promote p53 stabilization
\end{tabular}

Figure 5. Cartoon scheme of p53-Mdm2-MdmX interplay. Aberrant overexpression of Mdm2 RING domain may dimerize with the full-length Mdm2 or MdmX resulting in inhibition of Mdm2 E3 ligase activity, MdmX stabilization and impaired p53 transcription. 


\section{Materials and Methods}

\subsection{Plasmids}

Human full-length Mdm2, full-length MdmX, Mdm2 RING (residues 417-491), and MdmX RING (residues 416-490) domains were cloned into pcDNA3.1/YFP, pcDNA3.1/CFP, and pc-DNA3.1/FLAG expression vectors using a standard PCR subcloning technique.

\subsection{Cell Culture and Transfection}

Human osteosarcoma U2OS cells were grown in McCoy's medium supplemented with 10\% FBS. Cells were transfected with plasmids (10 $\mathrm{g}$ of DNA per $10 \mathrm{~cm}$ tissue culture plate) using PolyJet transfection reagent (SignaGen Laboratories, Rockville, MD, USA).

\subsection{Antibodies}

The antibodies for immunoblotting and co-immunoprecipitation were mouse monoclonal against Mdm2 (Santa Cruz SMP14, sc-965), MdmX (Millipore 8C6, 04-1555), p53 (Santa Cruz DO-1, sc-126), actin (Santa Cruz C-2, sc-8432), GAPDH (Santa Cruz 0411, sc-47724), YFP-tag (Abm G163), FLAG-tag (Sigma F3165), rabbit monoclonal against phosphorylated p53 (serine 15) (Cell Signaling \#9284), p21 (Santa Cruz C-19, sc-397), Bax (Cell Signaling \#2772), and rabbit polyclonal against FLAG-tag (Bethyl Laboratories A190-102A). To detect proteins of interest HRP-conjugated anti-mouse IgG (Jackson ImmunoResearch 115-035-166) and anti-rabbit IgG (Jackson ImmunoResearch 111-035-003) antibodies were used.

\subsection{Immunoblotting}

U2OS cells were transfected with YFP (empty vector), CFP-Mdm2 FL, CFP-MdmX FL, YFP-Mdm2 RING, and YFP-MdmX RING or FLAG (empty vector), FLAG-Mdm2 FL, FLAG-MdmX FL, FLAG-Mdm2 RING, and FLAG-MdmX RING. Cells were harvested $24 \mathrm{~h}$ post-transfection and lysed in RIPA buffer (50 mM Tris- $\mathrm{HCl}$ pH 8.0, $150 \mathrm{mM} \mathrm{NaCl}, 0.5 \%$ Nonidet P-40, 1X protease inhibitor cocktail (Roche, Mannheim, Germany)) followed by 2 sec sonication time with 10\% amplitude. Supernatants were boiled in SDS sample buffer for $5 \mathrm{~min}$ at $95^{\circ} \mathrm{C}$. Samples were resolved on $12 \%$ or 7.5\% SDS-PAGE, and immunoblotting was performed using antibodies described above.

\subsection{Fluorescent Microscopy}

U2OS cells were transfected with CFP-Mdm2 FL, CFP-MdmX FL, YFP-Mdm2 RING, and YFP-MdmX RING and grown on coverslips. The 24-hour post-transfection cells were fixed in $1 \%$ paraformaldehyde in PBS and permeabilized with $0.5 \%$ Triton- $X$ in PBS. Cells were washed with PBS two times. Images were obtained using Zeiss LSM 700 Laser Scanning microscope and LSM software ZEN 2010 (Zeiss, Germany).

\subsection{Co-Immunoprecipitation}

U2OS cells were transfected with CFP-Mdm2 FL and either FLAG-Mdm2 RING or FLAG-MdmX RING, CFP-MdmX FL, and either FLAG-Mdm2 RING or FLAG-MdmX RING to detect protein-protein interactions. Cells were harvested 24 hours post-transfection and lysed in RIPA buffer $(50 \mathrm{mM} \mathrm{Tris-HCl}$ $\mathrm{pH}$ 8.0, $150 \mathrm{mM} \mathrm{NaCl}, 0.5 \%$ Nonidet P-40, 1X protease inhibitor cocktail) followed by 2 sec sonication time with $10 \%$ amplitude. Cell lysates were incubated with a rabbit polyclonal anti-FLAG tag primary antibody for 2 hours followed by addition of pre-cleared protein A/G Plus-Agarose beads (Santa Cruz, sc-2003) for 1 hour. Immunoprecipitates were washed with RIPA buffer three times and then boiled in SDS sample buffer for $5 \mathrm{~min}$ at $95^{\circ} \mathrm{C}$ to release protein complexes from the beads. Samples were resolved on $12 \%$ SDS-PAGE, and immunoblotting was performed using antibodies described above. 


\subsection{RNA Expression Analysis}

U2OS cells were transfected with pcDNA3.1/FLAG empty vector, FLAG-Mdm2 FL, FLAG-Mdm2 RING, FLAG-MdmX FL, and FLAG-MdmX RING. Cells were harvested after 24- hour transfection and total RNA isolated with Trizol (ThermoFisher, Canada). cDNA was generated using Invitrogen SuperScript Reverse Transcriptase kit. SYBR green kit (SSoFast EveGreen Supermix) from Biorad (Hercules, CA) was used for qPCR. Relative mRNA expression levels were determined using $\Delta \Delta \mathrm{Ct}$ method. The following oligonucleotides were used:

\section{CDKN1A (5'TGAGCGATGGAACTTCGACT3' and 5'TTAGGGCTTCCTCTTGGAGA3'), BAX (5'AGACAGGGGCCCTTTTGCTTC3'and 5'TGCAGCTCCATGTTACTGTCC3'). GAPDH (5'AAGGTCATCCCTGAGCTGAAC3' and 5'ACGCCTGCTTCACCACCTTCT3').}

\subsection{Cell Cycle Analysis}

U2OS cells were transfected with pcDNA3.1/FLAG empty vector, FLAG-Mdm2 FL, FLAG-Mdm2 RING, FLAG-MdmX FL, and FLAG-MdmX RING. Following a 24-hour transfection, cells were fixed in $70 \%$ ethanol. After fixing, cells were washed with a staining buffer $(0.2 \%$ Triton X-100, $1 \mathrm{mM}$ EDTA in 1X PBS). Cells were mixed with staining buffer and RNAseA $(100 \mu \mathrm{g} / \mathrm{mL})$. Cells were stained by propidium iodide (Sigma Aldrich, P4864) for 1 hour. Samples were analyzed in a BD FACScalibur. Analysis was performed in CellQuest Pro (BD Biosciences, San Jose, CA, USA).

\subsection{Clonogenic Assay}

U2OS cells were transfected with pcDNA3.1/FLAG empty vector, FLAG-Mdm2 FL, FLAG-Mdm2 RING, FLAG-MdmX FL, and FLAG-MdmX RING. Following a 24-h transfection, 800 viable cells were seeded in 3-cm cell culture dishes in triplicate for each transfection event. After 10 days, the cells were fixed and stained by methylene blue dye $(0.25 \%$ methylene blue, $50 \%$ methanol). Colonies larger than $1 \mathrm{~mm}$ were counted. All the experiments were done in triplicate in each group and repeated. Statistical analyses were performed by using Sigma Stat software. All of the data was represented as Mean \pm SEM. Student's $t$-test was used to compare the values between two groups and one-way analysis of variance (ANOVA), was used to compare the multiple groups. $p<0.05$ was considered statistically significant.

Supplementary Materials: Supplementary materials can be found at http://www.mdpi.com/1422-0067/21/4/1309/ s1.

Author Contributions: Conceptualization, O.E. and Y.S.; methodology, O.E. and Y.S.; experiments and data curation, O.E., H.H.L. and K.M.; writing-original draft preparation, O.E.; writing-review and editing, O.E. and Y.S. All authors have read and agreed to the published version of the manuscript.

Funding: This research was funded by Leukemia and Lymphoma Society of Canada (LLSC) and the Natural Sciences and Engineering Research Council of Canada (NSERC) to Y.S.

Acknowledgments: We thank Weili Ma from Samuel Benchimol lab and Heyam Hayder from Chun Peng lab for advice on cell cycle and mRNA expression analysis.

Conflicts of Interest: The authors declare no conflict of interest. The funders had no role in the design of the study; in the collection, analyses, or interpretation of data; in the writing of the manuscript, or in the decision to publish the results.

\section{References}

1. Lane, D.P.; Fischer, P.M. Turning the key on p53. Nature 2004, 427, 789-790. [CrossRef]

2. Toledo, F.; Wahl, G.M. Regulating the p53 pathway: In vitro hypotheses, in vivo veritas. Nat. Rev. Cancer 2006, 6, 909-923. [CrossRef]

3. Vousden, K.H.; Lu, X. Live or let die: The cell's response to p53. Nat. Rev. Cancer 2002, 2, 594-604. [CrossRef]

4. Donehower, L.A.; Harvey, M.; Slagle, B.L.; McArthur, M.J.; Montgomery, C.A., Jr.; Butel, J.S.; Bradley, A. Mice deficient for p53 are developmentally normal but susceptible to spontaneous tumours. Nature 1992, 356, 215-221. [CrossRef] 
5. Feng, Z.; Hu, W.; Rajagopal, G.; Levine, A.J. The tumor suppressor p53: Cancer and aging. Cell Cycle 2008, 7, 842-847. [CrossRef]

6. Fukasawa, K.; Wiener, F.; Vande Woude, G.F.; Mai, S. Genomic instability and apoptosis are frequent in p53 deficient young mice. Oncogene 1997, 15, 1295-1302. [CrossRef]

7. Murphy, K.L.; Rosen, J.M. Mutant p53 and genomic instability in a transgenic mouse model of breast cancer. Oncogene 2000, 19, 1045-1051. [CrossRef]

8. Shadfan, M.; Lopez-Pajares, V.; Yuan, Z.M. MDM2 and MDMX: Alone and together in regulation of p53. Transl. Cancer Res. 2012, 1, 88-89.

9. Freedman, D.A.; Levine, A.J. Nuclear export is required for degradation of endogenous p53 by MDM2 and human papillomavirus E6. Mol. Cell. Biol. 1998, 18, 7288-7293. [CrossRef]

10. Yu, Z.K.; Geyer, R.K.; Maki, C.G. MDM2-dependent ubiquitination of nuclear and cytoplasmic P53. Oncogene 2000, 19, 5892-5897. [CrossRef]

11. Tollini, L.A.; Zhang, Y. p53 Regulation Goes Live-Mdm2 and MdmX Co-Star: Lessons Learned from Mouse Modeling. Genes Cancer 2012, 3, 219-225. [CrossRef] [PubMed]

12. Finch, R.A.; Donoviel, D.B.; Potter, D.; Shi, M.; Fan, A.; Freed, D.D.; Wang, C.Y.; Zambrowicz, B.P.; Ramirez-Solis, R.; Sands, A.T.; et al. $\mathrm{mdmx}$ is a negative regulator of p53 activity in vivo. Cancer Res. 2002, 62, 3221-3225. [PubMed]

13. Jones, S.N.; Roe, A.E.; Donehower, L.A.; Bradley, A. Rescue of embryonic lethality in Mdm2-deficient mice by absence of p53. Nature 1995, 378, 206-208. [CrossRef]

14. Migliorini, D.; Lazzerini Denchi, E.; Danovi, D.; Jochemsen, A.; Capillo, M.; Gobbi, A.; Helin, K.; Pelicci, P.G.; Marine, J.C. Mdm4 (Mdmx) regulates p53-induced growth arrest and neuronal cell death during early embryonic mouse development. Mol. Cell. Biol. 2002, 22, 5527-5538. [CrossRef]

15. Montes de Oca Luna, R.; Wagner, D.S.; Lozano, G. Rescue of early embryonic lethality in mdm2-deficient mice by deletion of p53. Nature 1995, 378, 203-206. [CrossRef]

16. Chavez-Reyes, A.; Parant, J.M.; Amelse, L.L.; de Oca Luna, R.M.; Korsmeyer, S.J.; Lozano, G. Switching mechanisms of cell death in mdm2- and mdm4-null mice by deletion of p53 downstream targets. Cancer Res. 2003, 63, 8664-8669.

17. Parant, J.; Chavez-Reyes, A.; Little, N.A.; Yan, W.; Reinke, V.; Jochemsen, A.G.; Lozano, G. Rescue of embryonic lethality in Mdm4-null mice by loss of Trp53 suggests a nonoverlapping pathway with MDM2 to regulate p53. Nat. Genet. 2001, 29, 92-95. [CrossRef]

18. Huang, L.; Yan, Z.; Liao, X.; Li, Y.; Yang, J.; Wang, Z.G.; Zuo, Y.; Kawai, H.; Shadfan, M.; Ganapathy, S.; et al. The p53 inhibitors MDM2/MDMX complex is required for control of p53 activity in vivo. Proc. Natl. Acad. Sci. USA 2011, 108, 12001-12006. [CrossRef]

19. Pant, V.; Xiong, S.; Iwakuma, T.; Quintas-Cardama, A.; Lozano, G. Heterodimerization of Mdm2 and Mdm4 is critical for regulating p53 activity during embryogenesis but dispensable for p53 and Mdm2 stability. Proc. Natl. Acad. Sci. USA 2011, 108, 11995-12000. [CrossRef]

20. Migliorini, D.; Danovi, D.; Colombo, E.; Carbone, R.; Pelicci, P.G.; Marine, J.C. Hdmx recruitment into the nucleus by $\mathrm{Hdm} 2$ is essential for its ability to regulate p53 stability and transactivation. J. Biol. Chem. 2002, 277, 7318-7323. [CrossRef]

21. Linke, K.; Mace, P.D.; Smith, C.A.; Vaux, D.L.; Silke, J.; Day, C.L. Structure of the MDM2/MDMX RING domain heterodimer reveals dimerization is required for their ubiquitylation in trans. Cell Death Differ. 2008, 15, 841-848. [CrossRef]

22. Mancini, F.; Gentiletti, F.; D’Angelo, M.; Giglio, S.; Nanni, S.; D’Angelo, C.; Farsetti, A.; Citro, G.; Sacchi, A.; Pontecorvi, A.; et al. MDM4 (MDMX) overexpression enhances stabilization of stress-induced p53 and promotes apoptosis. J. Biol. Chem. 2004, 279, 8169-8180. [CrossRef]

23. Yang, J.Y.; Zong, C.S.; Xia, W.; Wei, Y.; Ali-Seyed, M.; Li, Z.; Broglio, K.; Berry, D.A.; Hung, M.C. MDM2 promotes cell motility and invasiveness by regulating E-cadherin degradation. Mol. Cell. Biol. 2006, 26, 7269-7282. [CrossRef]

24. Yang, J.Y.; Zong, C.S.; Xia, W.; Yamaguchi, H.; Ding, Q.; Xie, X.; Lang, J.Y.; Lai, C.C.; Chang, C.J.; Huang, W.C.; et al. ERK promotes tumorigenesis by inhibiting FOXO3a via MDM2-mediated degradation. Nat. Cell Biol. 2008, 10, 138-148. [CrossRef]

25. Yap, D.B.; Hsieh, J.K.; Chan, F.S.; Lu, X. mdm2: A bridge over the two tumour suppressors, p53 and Rb. Oncogene 1999, 18, 7681-7689. [CrossRef] 
26. Mancini, F.; Teveroni, E.; Di Conza, G.; Monteleone, V.; Arisi, I.; Pellegrino, M.; Buttarelli, M.; Pieroni, L.; D'Onofrio, M.; Urbani, A.; et al. MDM4 actively restrains cytoplasmic mTORC1 by sensing nutrient availability. Mol. Cancer 2017, 16, 55. [CrossRef]

27. Fan, C.; Wang, X. Mdm2 Splice isoforms regulate the p53/Mdm2/Mdm4 regulatory circuit via RING domain-mediated ubiquitination of p53 and Mdm4. Cell Cycle 2017, 16, 660-664. [CrossRef]

28. Jacob, A.G.; O’Brien, D.; Singh, R.K.; Comiskey, D.F., Jr.; Littleton, R.M.; Mohammad, F.; Gladman, J.T.; Widmann, M.C.; Jeyaraj, S.C.; Bolinger, C.; et al. Stress-induced isoforms of MDM2 and MDM4 correlate with high-grade disease and an altered splicing network in pediatric rhabdomyosarcoma. Neoplasia 2013, 15, 1049-1063. [CrossRef]

29. Schuster, K.; Fan, L.; Harris, L.C. MDM2 splice variants predominantly localize to the nucleoplasm mediated by a COOH-terminal nuclear localization signal. Mol. Cancer Res. 2007, 5, 403-412. [CrossRef]

30. Volk, E.L.; Fan, L.; Schuster, K.; Rehg, J.E.; Harris, L.C. The MDM2-a splice variant of MDM2 alters transformation in vitro and the tumor spectrum in both Arf- and p53-null models of tumorigenesis. Mol. Cancer Res. 2009, 7, 863-869. [CrossRef]

31. Giglio, S.; Mancini, F.; Gentiletti, F.; Sparaco, G.; Felicioni, L.; Barassi, F.; Martella, C.; Prodosmo, A.; Iacovelli, S.; Buttitta, F.; et al. Identification of an aberrantly spliced form of HDMX in human tumors: A new mechanism for HDM2 stabilization. Cancer Res. 2005, 65, 9687-9694. [CrossRef]

32. Evans, S.C.; Viswanathan, M.; Grier, J.D.; Narayana, M.; El-Naggar, A.K.; Lozano, G. An alternatively spliced HDM2 product increases p53 activity by inhibiting HDM2. Oncogene 2001, 20, 4041-4049. [CrossRef]

33. Chipuk, J.E.; Kuwana, T.; Bouchier-Hayes, L.; Droin, N.M.; Newmeyer, D.D.; Schuler, M.; Green, D.R. Direct activation of Bax by p53 mediates mitochondrial membrane permeabilization and apoptosis. Science 2004, 303, 1010-1014. [CrossRef]

34. He, G.; Siddik, Z.H.; Huang, Z.; Wang, R.; Koomen, J.; Kobayashi, R.; Khokhar, A.R.; Kuang, J. Induction of p21 by p53 following DNA damage inhibits both Cdk4 and Cdk2 activities. Oncogene 2005, 24, 2929-2943. [CrossRef]

35. Egorova, O.; Mis, M.; Sheng, Y. A site-directed mutagenesis study of the MdmX RING domain. Biochem. Biophys. Res. Commun. 2014, 447, 696-701. [CrossRef]

36. De Graaf, P.; Little, N.A.; Ramos, Y.F.; Meulmeester, E.; Letteboer, S.J.; Jochemsen, A.G. Hdmx protein stability is regulated by the ubiquitin ligase activity of Mdm2. J. Biol. Chem. 2003, 278, 38315-38324. [CrossRef]

37. Nomura, K.; Klejnot, M.; Kowalczyk, D.; Hock, A.K.; Sibbet, G.J.; Vousden, K.H.; Huang, D.T. Structural analysis of MDM2 RING separates degradation from regulation of p53 transcription activity. Nat. Struct. Mol. Biol. 2017, 24, 578-587. [CrossRef]

38. Tournillon, A.S.; Lopez, I.; Malbert-Colas, L.; Naski, N.; Olivares-Illana, V.; Fahraeus, R. The alternative translated MDMX(p60) isoform regulates MDM2 activity. Cell Cycle 2015, 14, 449-458. [CrossRef]

39. Tao, W.; Levine, A.J. P19(ARF) stabilizes p53 by blocking nucleo-cytoplasmic shuttling of Mdm2. Proc. Natl. Acad. Sci. USA 1999, 96, 6937-6941. [CrossRef]

40. Li, C.; Chen, L.; Chen, J. DNA damage induces MDMX nuclear translocation by p53-dependent and -independent mechanisms. Mol. Cell. Biol. 2002, 22, 7562-7571. [CrossRef]

41. Gu, J.; Kawai, H.; Nie, L.; Kitao, H.; Wiederschain, D.; Jochemsen, A.G.; Parant, J.; Lozano, G.; Yuan, Z.M. Mutual dependence of MDM2 and MDMX in their functional inactivation of p53. J. Biol. Chem. 2002, 277, 19251-19254. [CrossRef]

42. Jin, Y.; Lee, H.; Zeng, S.X.; Dai, M.S.; Lu, H. MDM2 promotes p21waf1/cip1 proteasomal turnover independently of ubiquitylation. EMBO J. 2003, 22, 6365-6377. [CrossRef]

43. Zhang, Z.; Wang, H.; Li, M.; Agrawal, S.; Chen, X.; Zhang, R. MDM2 is a negative regulator of p21WAF1/CIP1, independent of p53. J. Biol. Chem. 2004, 279, 16000-16006. [CrossRef]

44. Jin, Y.; Zeng, S.X.; Sun, X.X.; Lee, H.; Blattner, C.; Xiao, Z.; Lu, H. MDMX promotes proteasomal turnover of p21 at G1 and early S phases independently of, but in cooperation with, MDM2. Mol. Cell. Biol. 2008, 28, 1218-1229. [CrossRef]

45. Lee, J.H.; Lu, H. 14-3-3Gamma inhibition of MDMX-mediated p21 turnover independent of p53. J. Biol. Chem. 2011, 286, 5136-5142. [CrossRef]

46. Priest, C.; Prives, C.; Poyurovsky, M.V. Deconstructing nucleotide binding activity of the Mdm2 RING domain. Nucleic Acids Res. 2010, 38, 7587-7598. [CrossRef] 
47. Alt, J.R.; Bouska, A.; Fernandez, M.R.; Cerny, R.L.; Xiao, H.; Eischen, C.M. Mdm2 binds to Nbs1 at sites of DNA damage and regulates double strand break repair. J. Biol. Chem. 2005, 280, 18771-18781. [CrossRef]

48. Riscal, R.; Schrepfer, E.; Arena, G.; Cisse, M.Y.; Bellvert, F.; Heuillet, M.; Rambow, F.; Bonneil, E.; Sabourdy, F.; Vincent, C.; et al. Chromatin-Bound MDM2 Regulates Serine Metabolism and Redox Homeostasis Independently of p53. Mol. Cell 2016, 62, 890-902. [CrossRef]

49. Wienken, M.; Moll, U.M.; Dobbelstein, M. Mdm2 as a chromatin modifier. J. Mol. Cell. Biol. 2017, 9, 74-80. [CrossRef]

50. Carrillo, A.M.; Bouska, A.; Arrate, M.P.; Eischen, C.M. Mdmx promotes genomic instability independent of p53 and Mdm2. Oncogene 2015, 34, 846-856. [CrossRef]

51. Kim, T.K.; Eberwine, J.H. Mammalian cell transfection: The present and the future. Anal. Bioanal. Chem. 2010, 397, 3173-3178. [CrossRef]

52. Jacob, A.G.; Singh, R.K.; Comiskey, D.F., Jr.; Rouhier, M.F.; Mohammad, F.; Bebee, T.W.; Chandler, D.S. Stress-induced alternative splice forms of MDM2 and MDMX modulate the p53-pathway in distinct ways. PLOS ONE 2014, 9, e104444. [CrossRef]

(C) 2020 by the authors. Licensee MDPI, Basel, Switzerland. This article is an open access article distributed under the terms and conditions of the Creative Commons Attribution (CC BY) license (http://creativecommons.org/licenses/by/4.0/). 